\title{
ÊXITOS E DESFECHOS NO ENSINO, PESQUISA E EXTENSÃO DO CURSO DE PEDAGOGIA DA FACELI DURANTE A PANDEMIA DA COVID-19
}

\author{
Successes and results in the teaching, research and extension of the faceli pedagogy \\ course during the covid-19 pandemic
}

\section{Éxito y resultados en la enseñanza, investigación y extensión del curso de pedagogía faceli durante la pandemia covid-19}

\author{
Joana Lúcia Alexandre de Freitas ${ }^{1}$, \\ Márcia Perini Valle ${ }^{2}$, \\ Valéria Vieira dos Santos $\operatorname{Pin}^{3}$.
}

\section{Resumo:}

Este artigo é um Relato de Experiência sobre os resultados obtidos nas disciplinas de Didática, Estágio Supervisionado e Fundamentos Teóricos e Metodológicos de Artes, Ciências e Geografia do curso de Pedagogia de uma Faculdade pública, municipal e gratuita localizada em um município no interior do Estado do Espírito Santo. Com o objetivo de fomentar trocas de experiências, relatos de experiências e reflexões sobre os processos de ensino e de aprendizagem realizados durante a pandemia no Ensino Superior, fez-se este estudo. Adotou-se como metodologia uma pesquisa qualitativa de cunho exploratório, adotando hipóteses indutivas com base em revisão bibliográfica para compreender as repostas de 49 acadêmicos em uma enquete sobre os processos de ensino e de aprendizagem no fim do primeiro semestre de 2020, na qual se escolheu a técnica de análise do discurso do sujeito coletivo para representar a concepção dos universitários. Dos resultados obtidos destacam-se: o aprimoramento no domínio de produção de recursos audiovisuais; a melhoria no desenvolvimento e no domínio da escrita científica em diversos gêneros textuais acadêmicos; a aquisição de habilidades e competências em aprender e ensinar através do ensino remoto e a ampliação de aprendizagens realizadas pelo uso intencional das Tecnologias da Informação e Comunicação (TICs). Todavia, há também desfechos frágeis como problemas de inclusão digital e de não adaptação ao ensino remoto os quais serviram para boas reflexões nesta pesquisa e que servirão para aperfeiçoar a Prática de Ensino de Professores Universitários e os da Educação Básica.

Palavras-chave: Ensino Remoto- Pandemia- Pedagogia.

\footnotetext{
${ }^{1}$ Doutoranda Em Educação em Ciências: Química da Vida e Saúde-UFSM, licenciada em Ciências Biológicas, professora de Ciências da Rede Municipal de ensino e titular de Prática de Ensino no Curso de Pedagogia da Faceli. E-mail: joana.freitas@acad.ufsm.br ORCID: https://orcid.org/00000002-1547-1505

${ }^{2}$ Pedagoga da Rede Municipal de Ensino e titular de Prática de Ensino de Educação Infantil no Curso de Pedagogia da Faceli. E-mail: marcia.valle@faceli.edu.br ORCID: https://orcid.org/0000-0002$1610-0036$

${ }^{3}$ Pedagoga da Rede Municipal de Ensino e titular na área de Didática e Estágio Supervisionado no Curso de Pedagogia da Faceli. E-mail: valeria.vieira@faceli.edu.br ORCID: https://orcid.org/0000$\underline{0002-5306-5583}$
} 


\title{
OO DEVIR EDUCAÇÃO
}

ISSN: 2526-849X

\begin{abstract}
:
This article is an Experience Report which talks about the obtained results in the disciplines of Didactics, Supervised Internship and Theoretical and Methodological Foundations of Arts, Sciences and Geography of the Pedagogy course of a public, municipal and free College located in a city in the interior of the State of Espírito Santo. In order to promote exchanges of experiences, experience reports and reflections about the teaching and learning processes carried out during the pandemic in Higher Education, this study was accomplished. Qualitative exploratory research was adopted as a methodology, having inductive hypotheses based on a literature review to understand the responses of 49 academics in a survey about the teaching and learning processes at the end of the first semester of 2020, in which it was chosen the technique of analyzing the discourse of the collective subject to represent the conception of university students. From the results obtained, the following stand out: the improvement in the domain of production of audiovisual resources; the improvement in the development and domaining of scientific writing in various academic textual genres; the acquisition of skills and competences in learning and teaching through the remote learning and the expansion of learning carried out by the intentional use of Information and Communication Technologies (ICTs). However, there are also fragile outcomes such as problems of digital inclusion and non-adaptation to remote learning which served for good reflections in this research and which will serve to improve the Teaching Practice of University Teachers and the Basic Education.
\end{abstract}

Keywords: Remote Learning- Pandemic- Pedagogy.

\section{Resumen:}

El artículo es un relato de experiencia sobre los resultados obtenidos en las disciplinas de Didáctica, Pasantía Supervisada y Fundamentos Teóricos y Metodológicos de las Artes, Ciencias y Geografía de la asignatura de Pedagogía de un Colegio público, municipal y gratuito ubicado en un municipio del interior del país. Estado de Espírito Santo. Con el fin de promover el intercambio de experiencias, relatos de experiencias y reflexiones sobre los procesos de enseñanza y aprendizaje llevados a cabo durante la pandemia en la Educación Superior, se llevó a cabo este estudio. Se adoptó como metodología una investigación exploratoria cualitativa, adoptando hipótesis inductivas a partir de una revisión de la literatura para comprender las respuestas de 49 académicos en una encuesta sobre los procesos de enseñanza y aprendizaje al final del primer semestre de 2020, en la cual se eligió la técnica de análisis del discurso del sujeto colectivo para representar la concepción de los estudiantes universitarios. De los resultados obtenidos se destacan: mejora en el dominio de producción de recursos audiovisuales; mejora en el desarrollo y dominio de la escritura científica en varios géneros textuales académicos; adquisición de habilidades y competencias para aprender y enseñar a través de la enseñanza a distancia y expansión del aprendizaje realizado por el uso intencional de las TIC. Sin embargo, también existen resultados frágiles como problemas de inclusión digital y no adaptación al aprendizaje a distancia que sirvieron de buenas reflexiones en esta investigación y que servirán para mejorar la Práctica Docente del Docente Universitario y también la de Educación Básica.

Palabras clave: Aprendizaje a distancia; Pandemia; Pedagogía.

Revista Devir Educação, Lavras-MG. Edição Especial, p.161-182, Set./2021. 


\section{OO DEVIR EDUCAÇÃO}

ISSN: 2526-849X

\section{Introdução}

A pandemia da Covid-19 deixou marcas profundas na vida das pessoas e na sociedade como mortes de entes queridos, além disso, piorou a economia e a Educação. Professores e estudantes tiveram que aprender a lidar com o novo normal ${ }^{4}$ e recriaram a forma de ensinar e aprender, auxiliando uns aos outros, trocando experiências, adaptando planos, ajustando atividades, criando videoaulas e alternativas para a continuidade do processo educativo devido à suspensão de aulas presenciais. Todos estes esforços precisam ser descritos e conhecidos e, portanto, com o objetivo de fomentar trocas de experiências, relatos de experiências e reflexões sobre os processos de ensino e de aprendizagem realizados durante a pandemia no Ensino Superior, fez-se este estudo.

Os dados aqui descritos trazem reflexões dos processos de ensino e de aprendizagem durante a formação inicial de professores pedagogos na pandemia, que incidem diretamente na constituição básica dos saberes destes profissionais, mas também na Educação Básica no decorrer do tempo através do exercício destes licenciados formados no período pandêmico. Estas razões estimularam três mestras a se reunirem para investigar e descrever a própria prática, com base na questão central: Quais foram os êxitos e desfechos das aulas de Prática de Ensino, de Estágio Supervisionado e de Didática que foram realizadas no período da Pandemia da Covid-19 no Curso de Pedagogia na Faculdade de Ensino Superior de LinharesES (Faceli)?

Perante esta incógnita, remeteu-se à memória e aos registros educacionais para descrever a prática exercida, no sentido de reflexão-ação-reflexão da práxis educativa, de modo que a comunidade científica perceba como se deu a formação inicial de alguns professores de uma cidade do Espírito Santo e que, certamente, refletirá na realidade de outras cidades que passaram pelos mesmos desafios e tiveram que se adaptar para garantir a continuidade do Ensino em Nível Superior.

\footnotetext{
${ }^{4}$ Novo normal, de acordo com Leal (2021) é a expressão criada pelos meios de comunicação de massa e profissionais da saúde para especificar mudanças nos costumes e nos comportamentos culturais da sociedade brasileira para controlar a disseminação do novo coronavírus, bem como novos meios de comunicação através da tecnologia que tendem a ficar após a pandemia como, por exemplo: ao invés de cumprimentar com abraço e beijo optar por leves toques de cotovelos ou de mão fechada; uso de salas virtuais para conversas formais e informais tanto para uso escolar quanto profissional e familiar, drive tour (ir a ambientes e não sair do carro) para tomar vacina, coletar exames, assistir shows, exposições etc.
}

Revista Devir Educação, Lavras-MG. Edição Especial, p.161-182, Set./2021. 


\section{OO DEVIR EDUCAÇÃO}

ISSN: 2526-849X

Este estudo está configurado em três eixos: O primeiro são os Êxitos e desfechos na Didática; O segundo são Êxitos e desfechos no Estágio Supervisionado; O terceiro são Êxitos e desfechos nas Práticas de Ensino de Artes, Ciências e de Geografia. Deste modo, o leitor terá uma dimensão maior do processo educativo que ocorreu com os mesmos grupos de acadêmicos de licenciatura em Pedagogia em uma Faculdade do interior do Espírito Santo. Apresentamos por olhares diferentes e por diferentes eixos temáticos, os processos de ensino e de aprendizagem destes futuros pedagogos formados no bojo dos desafios sociais da pandemia da Covid-19.

De acordo com Freitas e Macedo (2020), a Faceli é uma Faculdade pública municipal localizada em Linhares, cidade do extremo norte capixaba com mais de 180 mil habitantes onde se instalaram empresas nacionais e multinacionais que movimentam a economia local. Ademais, há grande potencial de petróleo e gás, fato que possibilita investir na Educação com oferta de Ensino Superior. A instituição tem mais de 1000 estudantes distribuídos nos três turnos dos cursos de Administração, Direito e Pedagogia.

Nesta pesquisa, apresentaremos os êxitos e desfechos apenas no Curso de Pedagogia, com estudantes que cursaram o primeiro semestre nas disciplinas de Didática, Estágio Supervisionado, Fundamentos Teóricos e Metodológicos de Artes (FTMA), Fundamentos Teóricos e Metodológicos de Ciências (FTMC) e de Fundamentos Teóricos e Metodológicos de Geografia (FTMG), bem como com as respectivas docentes que ministraram estes componentes curriculares.

A metodologia classifica-se como pesquisa qualitativa de cunho exploratório, adotando hipóteses indutivas com base em revisão bibliográfica para compreender os fenômenos percebidos no grupo analisado (GIL, 2019). Para análise dos dados, escolheu-se a técnica de análise do discurso do sujeito coletivo (DSC) - (FIGUEIREDO; CHIARI; GOULART, 2013) para representar a concepção de 49 acadêmicos que participaram de uma enquete via Formulário Google sobre os processos de ensino e de aprendizagem no fim do primeiro semestre de 2020. Os resultados obtidos em 2020.1 refletiram em tomadas de decisão e planejamento para 2020.2 e para o ano de 2021 que trouxeram experiências, êxitos e desfechos que ressignificaram a prática do Ensino Superior na Faceli no curso de Pedagogia.

\section{Os desafios impostos pela COVID-19 no curso de Pedagogia da Faceli}




\section{1. Êxitos e desfechos na disciplina de Didática}

O Ensino Superior precisou se reinventar para oferecer novas oportunidades de acesso ao conhecimento científico durante a pandemia da Covid-19. Isso obrigou os profissionais do curso de Pedagogia da Faceli a repensar, de forma emergencial, uma adaptação das práticas e reflexões com os estudantes neste novo contexto.

Consoante com a Portaria do MEC n $343 / 2020$ que orientou a substituição das disciplinas presenciais, em andamento, por aulas que utilizassem meios e tecnologias de informação e comunicação, foi instituído na Faceli o Ensino Remoto ${ }^{5}$ com o intuito de amenizar possíveis perdas, tanto emocionais quanto cognitivas, por parte dos estudantes e professores. "A pandemia afeta estudantes e professores, de modo que todos estão sofrendo modificações e interrupções em suas vidas, [...]. Portanto, é preciso compreensão de ambos os lados, pois todos estão passando por momentos atípicos e de adaptação" (RONDINI; PEDRO; DUARTE, 2020, p. 48).

Este cenário, levou à construção de um Plano de Ações a ser implementado em face à situação da Covid-19, responsável pela suspensão das aulas e demais atividades acadêmicas presenciais, elaborado pelo Grupo de Trabalho Multissetorial (GTM). Nesse sentido, a metodologia presencial analógica foi substituída pelo ensino remoto emergencial “[...] apropriando-se de tecnologias digitais intuitivas e de fácil acesso para os docentes e discentes. Após um momento de discussão e apresentações de algumas propostas, optou-se em utilizar a Plataforma Google Sala de Aula" (FUNDAÇÃO FACELI, 2020, p. 11).

Para superarmos o primeiro momento do Ensino Remoto emergencial para um segundo momento mais planejado, ou seja, para o ensino remoto intencional, foi imprescindível que houvesse uma liderança forte, humana e o envolvimento de todos no processo. Além do social, essa superação só foi possível por meio de ações como a implantação do Ambiente Virtual de Aprendizagem (AVA) Faceli, capacitação docente para o uso de novas tecnologias, atendimento aos estudantes com dificuldade de acesso ao ensino remoto, dentre outras ações.

\footnotetext{
${ }^{5}$ Ensino Remoto na concepção de Santos (2020) é uma forma de propagar os conhecimentos em caráter excepcional e emergencial devido à pandemia do coronavírus, que ocorre através de apostilas ou por encontros virtuais que visam manter a rotina de estudo e o processo de ensino e aprendizagem.
}

Revista Devir Educação, Lavras-MG. Edição Especial, p.161-182, Set./2021. 


\section{OO DEVIR EDUCAÇÃO}

ISSN: 2526-849X

Dessa forma, a metodologia adotada no ensino remoto intencional buscou colocar a interação entre o estudante e o saber sistematizado como protagonista nos processos de ensino e de aprendizagem. Consoante com Morán (2015) cabe definir bem os objetivos e, aliados a eles, oferecer uma metodologia que seja capaz de assegurar a concretização desses objetivos através de atividades significativas e essenciais.

O ensino remoto intencional possui o seu foco no planejamento estratégico com relação à aprendizagem dos estudantes e não simplesmente com a entrega de conteúdos e de aula, ou seja, busca se ajustar a rotina familiar e aos possíveis problemas de conectividade que estudantes e professores possam vir a ter, visando garantir os processos de aprendizagem.

Dessa forma, em conformidade com a Resolução CNE/CP N 2/2020, Art. $3^{\circ}$, alíneas XV e XVI foram utilizadas atividades on-line síncronas e assíncronas ${ }^{6}$ (BRASIL, 2020) para o ensino remoto intencional. O momento síncrono aconteceu por meio de aula ao vivo (lives) videoconferência, chats/salas de bate papo, dentre outras. Para o momento assíncrono foram utilizados links para conteúdos de sites ou arquivos, publicação de vídeo aulas, slides, podcast, entre outras modalidades de interação vinculadas pelo AVA Faceli. A interatividade assíncrona foi realizada através de atividades avaliativas, de provas, de questionários dinâmicos, de jogos, de fóruns de discussão, entre outros (FUNDAÇÃO FACELI, 2020).

Dada a necessidade do uso de novas tecnologias, se fez imprescindível a organização do Guia de Aprendizagem com a finalidade de padronizar a forma de apresentação das diferentes disciplinas no AVA. Elaborado a partir do plano de ensino da disciplina, o guia apresenta objetividade nos conteúdos, das habilidades e as atividades que serão desenvolvidas no decorrer do tempo em cada disciplina (FUNDAÇÃO FACELI, 2020, p. 15).

Observou-se que um dos grandes desafios enfrentados foi a falta de familiaridade que alguns docentes e estudantes tinham com ambientes virtuais, mesmo com as capacitações realizadas. Este fato confirmam as palavras de Morán (2015, p. 28) "Muitos demoram para adaptar-se aos ambientes virtuais cheios de materiais, atividades, informações. Sentem falta

\footnotetext{
${ }^{6}$ Momentos ou atividades assíncrona, que de acordo com Santos (2020) são atividades e estudos realizados pelos estudantes sob orientação do professor no tempo (cronos) e espaço externos aos ambientes formais de ensino onde julgam conveniente para criar ou recriar a mensagem deixada por seu tutor. As atividades síncronas são comunicações estabelecidas em tempo real e em local específico da web, que embora não democratize a participação de todos devido ao delay (atraso) e a falhas de conexão com a internet, possibilita troca de ideias e realização de dinâmicas entre os sujeitos.
} 


\section{OO DEVIR EDUCAÇÃO}

ISSN: 2526-849X

do contato físico, da turma [...]. O ambiente digital para quem não está acostumado é confuso, distante, pouco intuitivo e agradável". É importante lembrar que o apoio, tanto por parte da coordenação de curso quanto de outros colegas mais hábeis, muito ajudou na superação destas dificuldades.

Para registrar a frequência dos estudantes e como forma de acompanhar o processo de aprendizagem foram propostas atividades interativas para eles realizarem durante as aulas remotas. Para tanto, cada aula elaborada e postada pelo professor deveria conter uma atividade proposta a ser realizada (composta de, no máximo, cinco questões que abordassem o essencial do conteúdo ministrado). (FUNDAÇÃO FACELI, 2020).

Em relação ao processo de avaliação da aprendizagem, cada professor na Pedagogia aplicou, de forma virtual, a avaliação da disciplina ministrada, utilizando-se do AVA Faceli. Nas avaliações parciais, o docente pôde utilizar diversos mecanismos/ferramentas disponíveis no ambiente virtual, conforme a especificidade da disciplina.

Concomitante ao movimento de implementação do ensino remoto intencional, uma preocupação sempre foi o atendimento aos estudantes com dificuldade de acesso ao ensino remoto. Dessa forma, foi possível identificar essa demanda e propor as seguintes alternativas, dependendo do caso: disponibilização de computador com acesso à Internet, no laboratório de informática ou na biblioteca da faculdade; disponibilização de material impresso a ser retirado pelo estudante; gravação em pen drive ou outro dispositivo com os materiais disponibilizados no AVA Faceli (FUNDAÇÃO FACELI, 2020).

A sociedade como um todo, em diferentes proporções, tem sido afetada pela pandemia do novo coronavírus ${ }^{7}$. Entendemos que muitos dos impactos trazidos por ela provocaram uma transformação que será permanente em todo o mundo e, especificamente, em nossa comunidade acadêmica. Muitas mudanças as quais nós tivemos que nos adaptar repentinamente, devem perdurar mesmo após o final da pandemia. $\mathrm{O}$ momento é assustador, mas, ao mesmo tempo, nos traz muitos aprendizados que nos acompanharão.

\footnotetext{
${ }^{7}$ Novo coronavírus de acordo com a Organização Mundial de Saúde (OMS) é o nome dado ao vírus da família (SARS-CoV-2), causador da doença infecciosa denominada de COVID-19, que tem como principais sintomas febre, cansaço e tosse seca (BRASIL-UNA-SUS, 2020).
}

Revista Devir Educação, Lavras-MG. Edição Especial, p.161-182, Set./2021. 


\section{OO DEVIR EDUCAÇÃO}

ISSN: 2526-849X

Nesse contexto, a plataforma AVA hoje é uma ferramenta importante nos processos de ensino e de aprendizagem e a sua incorporação na dinâmica, quanto da volta ao ensino presencial, é algo bem real. "Todas as iniciativas de ensino remoto utilizadas durante a luta contra a Covid-19 podem ser sementes para a transformação digital e cultural tão necessária no ensino, unindo práticas pedagógicas inovadoras, como o aprendizado híbrido e metodologias ativas [...]” (ISOTANI ${ }^{8}$ apud OLIVEIRA; SILVA; SILVA, 2020, p. 31).

As modalidades de ensino remoto e à distância que, muitas vezes, enfrentavam alguns obstáculos para a sua implantação, é hoje a engrenagem essencial nas Instituições de Ensino Superior que adotou as aulas virtuais para garantir a rotina de estudos acadêmicos. Com base em reflexões da ação, principalmente quanto à adaptação dos estudantes, é fato que permaneceremos com algumas atividades on-line e exploraremos ainda mais o universo tecnológico usando novas possibilidades e habilidades que favorecem o ensino.

\section{2. Êxitos e desfechos na disciplina de Estágio Supervisionado}

O Estágio Supervisionado é o momento em que o estudante terá as suas primeiras experiências in loco, ou seja, em um ambiente real no qual será capaz de vivenciar e aprender sobre a prática profissional, em forma de oportunidade de colocar em ação toda a teoria aprendida dentro da sala de aula. Consoante com Pimenta e Lima (2017, p. 36-37), “[...] o estágio curricular é atividade teórica de conhecimento, fundamentação, diálogo e intervenção na realidade, esta, sim, objeto da práxis. Ou seja, é no contexto da sala de aula, da escola, do sistema de ensino e da sociedade que ocorre a práxis".

Nesse sentido, o estágio no curso de Pedagogia oportuniza ao acadêmico vivenciar e refletir sobre as práticas educativas nas diferentes etapas de ensino buscando conhecer as especificidades da docência na Educação Infantil e nos Anos Iniciais do Ensino Fundamental, bem como a participação em processos de gestão em ambientes escolares e não escolares. A partir de 2020, em função da pandemia da Covid-19, as práticas educativas escolares

\footnotetext{
${ }^{8}$ Palestra proferida pelo professor Seiji Isotani, do Instituto de Ciências Matemáticas e de Comunicação (ICMC - USP) no evento Webinar 8 - SEB - Uso de TICs nas Escolas de Educação Básica da série webnários Educação no mundo 4.0, organizada pelo Ministério da Educação no dia 6 de maio de 2020. Disponível em: https://www.youtube.com/watch?v=f1qRWNRaH7k\&feature=youtu.be.
} 


\section{OO DEVIR EDUCAÇÃO}

ISSN: 2526-849X

ganharam uma nova configuração, pois as instituições de ensino tiveram que se reinventar na forma de ensinar, portanto adaptaram novos modelos de trabalho, muitos realizados remotamente.

Diante disto, o Ministério da Educação divulgou documentos que autorizaram a substituição de aulas presenciais e a realização do Estágio Supervisionado por aulas remotas (mais especificamente a Portaria $N^{\circ} 544 / 2020$ e a Resolução CNE/CP No 2/2020). As IES seguindo o protocolo estratégico de prevenção e controle da COVID-19, não puderam mais receber os licenciandos como estagiários em seu interior.

Perante este cenário, o componente curricular de Estágio Supervisionado teve que se adequar ao Ensino Remoto. No início ficamos inseguros em proporcionar atividades não presenciais para uma disciplina que é, essencialmente, prática. Mas uma verdade sempre nos motivou: a de tornar os nossos acadêmicos, desde o seu primeiro momento de Estágio Supervisionado, como os protagonistas do próprio ensino. De modo análogo, os professores da rede municipal tiveram o mesmo intuito com as crianças; buscaram conhecê-las (via WhatsApp) para refletir sobre como ensinar na pandemia. Assim, da forma a mais prática possível, realizaram atividades significativas que tinham as interações e brincadeiras como eixos norteadores do trabalho pedagógico.

Após um ano, desde que iniciamos o trabalho remoto com os acadêmicos da Faceli, percebemos o quanto todos nós, professores e estudantes, precisaríamos nos reinventar. $\mathrm{O}$ trabalho foi desenvolvido de forma assíncrona e síncrona, deste modo os acadêmicos mantiveram o ritmo de estudos, observando a duração de cada bloco de conteúdo postado; dias e horários das videoconferências, pelo qual recebiam orientação. Entretanto, as orientações para que o estudante obtivesse sucesso girou em torno da necessidade de organização quanto aos horários destinados ao estudo. Todos sabem que, em casa, isso não é tão fácil. Mas a ideia é a de que o estudante assumisse compromisso com os estudos assim como todos à sua volta deveriam estar cientes dos momentos destinados para o curso.

Deste modo, a partir de reuniões e pesquisas quanto ao formato das atividades não presenciais destinadas ao Estágio Supervisionado, o primeiro modelo foi lançado, seguido de orientações para cada uma das atividades propostas: produção de resenhas de textos relacionados à etapa do estágio; realização de cursos on-line em conformidade com a área do 


\section{OO DEVIR EDUCAÇÃO}

ISSN: 2526-849X

estágio; elaboração de sequências didáticas/projetos didáticos; resolução de situaçãoproblema; produção de material didático e aplicação/simulação de atividades e produção de relatórios reflexivos. Por fim, através de um vídeo, os acadêmicos socializaram as aprendizagens ocorridas na disciplina de Estágio Estagio (FUNDAÇÃO FACELI, 2020).

A disciplina de Estágio Supervisionado I, especificamente na Educação Infantil, contou com um trabalho interdisciplinar com a disciplina de Atividades Práticas V. As ações foram planejadas de forma que contribuíssem com a prática pedagógica desenvolvida na rede municipal de ensino de Linhares/ES. Os estudantes foram orientados a construírem atividades conforme as orientações dadas pela coordenação do setor de Educação Infantil da rede municipal de ensino.

Dessa forma, foram elaboradas Atividades Pedagógicas Não Presenciais - APNPs de acordo com os objetivos de aprendizagem e desenvolvimento selecionados nos diferentes Campos de Experiências dos documentos oficiais (BNCC, Currículo do Espírito Santo e Orientações Curriculares da rede municipal de ensino de Linhares/ES). A partir de uma sequência didática, os acadêmicos produziram vídeos contando histórias, ensinando uma brincadeira ou, ainda, apresentando uma canção. Para aplicar os materiais produzidos, foi firmada uma parceria com a Secretaria Municipal de Educação, para que dois (Centro de Educação Infantil Municipal) CEIM da rede, de forma experimental, utilizassem as APNPs e os vídeos produzidos pelos acadêmicos sob orientação das mestras e com apoio dos professores colaboradores das instituições.

As famílias das crianças receberam os vídeos feitos pelos acadêmicos e as atividades elaborada pelos professores regentes através do grupo de WhatsApp, canal de comunicação entre os docentes e discentes. As famílias que não aderiram ao aplicativo para receber os arquivos digitais, resgataram atividades impressas na escola para desenvolverem momentos pedagógicos com as crianças.

Uma orientação sempre bem reforçada é a de que a família deve procurar manter uma rotina de atividades escolares com as crianças. Assim, a linguagem e os processos para explicar às famílias como desenvolver as atividades foi feita com muita atenção já que sabemos que não é nada fácil manter uma rotina de estudos em casa, sobretudo para as 


\section{OO DEVIR EDUCAÇÃO}

ISSN: 2526-849X

crianças. Aqui, cabe ao professor se concentrar nas orientações às famílias, sem esperar resultados rápidos.

A comunicação com os pais e/ou responsável deve ter o intuito de orientar, sugerir e explicar a importância do desenvolvimento das atividades propostas e enviadas para as crianças, a partir dos objetivos de aprendizagem e desenvolvimento que são definidos para a idade do infante, sempre de forma lúdica, sem perder de vista os eixos norteadores do trabalho na Educação Infantil, as interações e brincadeira (BRASIL, 2009).

E, assim, procuramos ressignificar as disciplinas de Atividades Práticas V e de Estágio Supervisionado, orientando os estudantes, mesmo à distância e fora da Faculdade, com tudo o que os aproxima de uma prática pedagógica intencional presente nos dias de hoje, sempre acreditando que a brincadeira tem sentido cognitivo e que deve continuar alcançando as nossas crianças de forma significativa.

A partir da experiência vivenciada temos a intenção de continuar desenvolvendo, nessas disciplinas, um trabalho interdisciplinar associado ao uso de ferramentas digitais para a produção de materiais didáticos, ressignificando a formação inicial dos futuros professores, pois não sabemos se, no futuro, teremos novos enfrentamentos dentro desta situação de ensino e de aprendizagem. Então, nada melhor do que nesse momento nos desafiarmos e nos apropriarmos de novos saberes.

\section{3.- Exitos e desfechos nas práticas das disciplinas de Artes, de Ciências e de Geografia.}

Nas aulas das disciplinas de Fundamentos Metodológicos de Artes (FTMA), de Geografia (FTMG) e de Ciências (FTMC) também foram utilizadas aulas assíncronas por meio de videoaulas produzidas pela regente das disciplinas, artigos, livros e documentos oficiais para estudos, via plataforma virtual de aprendizagem, além de um plano de estudo denominado de Guia de Aprendizagem. Também ocorreu momento síncrono ora semanal ora quinzenal, mediante a necessidade educacional deles.

Nos momentos síncronos discentes e docentes compartilharam a dor da perda de familiares para a COVID-19, o medo de contrair o vírus e também momentos valiosos para a continuidade da aprendizagem. Nestes encontros, as dúvidas sobre conceitos foram 


\section{OO DEVIR EDUCAÇÃO}

ISSN: 2526-849X

esclarecidas para dar continuidade ao processo de formação dos futuros pedagogos. Realizouse o uso intencional das TICs, pois como afirma Morán (2018) através da tecnologia o estudante pesquisa, aprende, interage e compartilha saberes que vão além de apenas estabelecer comunicação entre os diversos sujeitos, pois a web possibilita o discente ler, refletir, comparar diversas informações e sintetizá-las com base em diversas fontes.

Todavia, como os alunos avaliaram esta mudança abrupta no processo de ensino e aprendizagem? Em busca de respostas, no final do primeiro semestre de 2020, 100 estudantes dos três FTMs foram convidados a avaliar o semestre e, ao mesmo tempo, fazer uma autoavaliação. Porém, apenas 49 acadêmicos responderam ao questionário. No instrumento de coleta de dados havia ao todo seis itens, sendo 3 objetivos e 3 discursivos.

Os resultados apontam que os participantes da enquete tem idades que variam de 18 a 50 anos, porém, a maioria são jovens. Grande parte reside em Linhares, alguns são de cidades vizinhas como Sooretama, Jaguaré e São Mateus que também são do extremo norte capixaba. Grande parte dos estudantes está cursando a primeira graduação e atua como estagiários na rede municipal de ensino. Muitos conciliam estudos com o trabalho para complementar a renda familiar, a maioria são de classe média à classe média-baixa.

Dentre os itens, perguntou-se sobre o tempo que destinaram aos estudos e como estudaram em 2020.1. Neste quesito, 23 acadêmicos (46,9\%), quase metade dos entrevistados, afirmaram que estudaram muito; $13(26,5 \%)$ disseram que estudaram mais ou menos e 13 $(26,5 \%)$ admitiram ter estudado tempo insuficiente; neste último grupo 9 discentes $(18,4 \%)$ declararam que não conseguiram se adaptar ao ensino remoto.

O que chama atenção nestes dados são os estudantes que não conseguiram se adaptar ao ensino remoto e os que não conseguiram tempo para estudar, afinal, em casa há o convívio com os familiares, problema de conexão, falta de espaço adequado, entre outros incômodos. Santos (2019, p. 105) elucida que as salas de aula no Brasil estão adaptadas com estrutura para aula expositiva, em que todos os estudantes estão enfileirados e acomodados para ouvir a explanação do mestre de forma passiva. "Esse espaço estimula a obediência, a concentração em quem fala na frente e a repetição e cópia do que é palestrado". Isso está internalizado no estudante e romper com este modelo mental para alguns deles é difícil, necessita de autodisciplina e colaboração da família que, por sua vez, nem sempre colabora.

Revista Devir Educação, Lavras-MG. Edição Especial, p.161-182, Set./2021. 


\section{OO DEVIR EDUCAÇÃO}

ISSN: 2526-849X

Se somarmos estes dois grupos, quase metade dos entrevistados não estudou o tempo suficiente para aquisição dos saberes esperados para a etapa. Isso é preocupante visto que serão professores e necessitarão lecionar saberes que não foram devidamente consolidados na graduação. Com base nas ideias de Schneider (2019, p. 78) "O fato de não termos a educação ideal (não no sentido de perfeição, mas de qualidade) torna cada um de nós uma peça fundamental e, com isso, carrega-nos de responsabilidades, afinal, está também em nossas mãos a mudança que tanto queremos". Sendo assim, a mudança no método de ensino não exime cada um dos estudantes de reinventar técnicas para estudar de acordo com suas condições financeiras e temporais.

Considerando que antes do ensino remoto os estudantes estudavam presencialmente 4 horas semanais nas disciplinas de fundamentos, questionou-se quanto tempo em horas eles dedicam aos estudos dos FTMs no ensino remoto. Dentre os 49 alunos, 17 (34,7\%) dos estudantes declararam que dedicaram as mesmas 4 horas semanais; outros $17(34,7 \%)$ afirmaram que dedicaram cerca de 10 horas semanais; $11(22,4 \%)$ disseram estudar mais de 10 horas semanais e apenas $4(8,2)$ declararam estudar cerca de 2 horas. Provavelmente, eles compreenderam mal este item, pois se questionou em relação aos FTMs e não em relação a todas as disciplinas. Se eles dedicaram 10 horas apenas para os FTMs quanto tempo destinaram para as demais disciplinas?

Outro resultado intrigante é os que admitiram estudar cerca de 2 horas: se é para uma disciplina em específico talvez seja suficiente, mas se é para todas as disciplinas do semestre, assim como possivelmente interpretou os demais, este tempo é insuficiente para aprender todos os saberes necessários, o que denota, novamente, fragilidade na aprendizagem destes estudantes.

Para o sucesso do Ensino Remoto é imprescindível parceria e comprometimento de docentes e discentes. Ambos devem estar em comum acordo para garantir esforços em prol da aprendizagem. Neste tradado, o docente tem a função de oferecer materiais de qualidade, sugerir referências e dar assessoria nos momentos de dificuldade; os acadêmicos, por sua vez, tem o papel de gerenciar o próprio tempo para conseguir o andamento do estudo, solicitando orientação do mestre ou realizando pesquisas na literatura científica para garantir a aquisição dos tópicos previstos no ementário do componente curricular. 


\section{OO DEVIR EDUCAÇÃO}

ISSN: 2526-849X

Outra questão que se fez necessário pesquisar foi se tiveram acesso à internet $\mathrm{e}$ o meio pelo qual os estudantes tiveram acesso às aulas síncronas e ao material disponibilizado on-line para aulas assíncronas. Os resultados foram: $45(91,8)$ dos 49 entrevistados tiveram acesso à internet; a maioria, 43 (87,8\%), teve acesso ao material e participou dos momentos síncronos pelo celular; $31(63,3 \%)$ dos estudantes estudaram utilizando o computador com acesso internet; $4(8,2 \%)$ deles usaram tablet com acesso à internet e $3(6,1 \%)$ não tiveram acesso à internet na maior parte do semestre.

Este dado revela que nem todos os estudantes estão incluídos digitalmente na Faceli. No grupo entrevistado foram poucos, mas em toda a Faculdade e demais escolas da Educação Básica e do Ensino Superior, eles são muitos. O IBGE (2019) revela que cerca de 93,2\% dos domicílios brasileiros têm telefone celular móvel e somente $79,1 \%$ acesso à internet. Deste modo, mais de $11 \%$ dos brasileiros não têm acesso à internet pelo celular. Se analisar o acesso por computador e tablet, o índice aumenta ainda mais. Esta considerável parcela de brasileiros têm dificuldades para se comunicar e para obter informação e conhecimento, principalmente no momento pandêmico.

Para amenizar o problema de exclusão digital, a Faceli disponibilizou materiais impressos, pen drive ou $C D s$ com videoaulas para serem assistidas em aparelhos de $D V D$ ou em televisões que tenham entrada USB. Não foi a melhor solução, mas foi a alternativa que encontraram. Similar a esta ação, outras instituições brasileiras disponibilizaram material impresso, inclusive na Educação Básica do próprio município, como afirma Freitas (2020).

Para o registro de presença e para avaliar os processos de ensino e de aprendizagem, solicitou-se que os estudantes fizessem atividades semanais para serem postadas no ambiente virtual de aprendizagem ou pelo WhatsApp. Os alunos que estudaram por material impresso também fizeram trabalhos acadêmicos e os entregaram ao coordenador do curso para serem corrigidas pelo professor.

Três itens discursivos foram categorizados e expostos de acordo com a técnica de DSC para facilitar a apresentação dos dados (FIGUEIREDO; CHIARI; GOULART, 2013). Quando questionados sobre a maior dificuldade encontrada, os 49 estudantes apontaram diferentes pontos, a saber:

17 alunos: “- Excesso de atividades para serem entregues em pouco tempo”. 


\section{OO DEVIR EDUCAÇÃO}

ISSN: 2526-849X

13 alunos: "- Dificuldade de fazer resenha crítica, paper [gêneros textuais poucos usados no presencial] e de gravar e editar vídeos como apresentação de seminário."

13 alunos: "-Dificuldade de participar das aulas síncronas, de estudar em casa dividindo espaço e atenção com os familiares, além de conciliar o trabalho [alguns acadêmicos arrumaram empregos no período que estariam estudando no presencial] com o estudo".

01 alunos: "-Não tive dificuldade".

05 alunos: "-Falta de internet ou de mídias como computador e tablet para acessá-la $e$ de estudar apenas com o celular para pesquisa e realização dos trabalhos acadêmicos".

A maioria dos estudantes reclamou de excesso de atividades e, por conseguinte, a mestra passou a cobrar atividades quinzenais ao invés de semanalmente. De fato, se todos os professores cobrarem atividades semanalmente, no decorrer de um mês, os estudantes teriam feito muitas atividades que, necessariamente, não garantem aprendizagem. A mudança do presencial para o remoto, fez com que a mestre optasse por decisões rápidas, e neste sentido, não foi a mais sensata para o momento. Todavia, ouvir os discentes quanto à quantidade e qualidade de atividade, certamente, fez melhorar o processo de ensino para o semestre de 2020.2 em que duas, das três turmas, continuaram estudando com a mesma docente.

A segunda parcela expressiva de estudantes apontou dificuldades em fazer atividades textuais que no presencial eram pouco cobradas. Isto pode ser considerado como positivo, afinal, foram desafiados a conhecerem novos gêneros textuais acadêmicos e a desenvolver habilidades audiovisuais que não detinham, o que os tornou competentes para se for preciso, elaborar materiais para os estudantes da Educação Básica, seja no estágio ou no exercício da função.

A pandemia da COVID-19 pode durar por alguns anos e com a rotineira suspensão de aulas mediante o aumento de mortes, requer que todos os educadores dominem as TICs para levar conhecimento aos seus estudantes, logo, apreender esta tecnologia tornará os futuros pedagogos ainda mais competentes nesta nova demanda educacional. "O celular está massivamente presente na rotina dos indivíduos nesse cenário de pandemia e distanciamento social, e também é recurso para o ensino a distância." (SILVA et al, 2021, p. 6). Na ideias destes autores, podemos perceber que o uso de celular, da internet e de aplicativos para fazer e compartilhar recursos audiovisuais é uma tendência educacional tanto na Educação Básica 


\section{OO DEVIR EDUCAÇÃO}

ISSN: 2526-849X

quanto no Ensino Superior. Logo, todos que pretendem ser professor no século XXI precisam ser letrados nos recursos tecnológicos.

Apenas um estudante afirmou não ter tido dificuldade. Diante do todo, é muito pequeno o número de estudantes satisfeitos com as modificações no processo educativo. Muitos acadêmicos não participaram efetivamente dos recursos audiovisuais o que dificultou também a comunicação deles no decorrer do processo educativo. Fato que comprova as ideias de Morán (2018) de que o uso das TICs é importante para a realização de metodologias ativas e que, com a pandemia, tornaram-se essenciais.

Perguntou-se o que poderia melhorar nos processos de ensino e de aprendizagem para o próximo semestre e os 49 participantes afirmaram:

31 alunos: "- Produzir videoaulas menores, com textos de apoio mais sucintos $e$ objetivos. Menos atividade com mais tempo para fazê-las”.

02 alunos: "-Criar uma plataforma institucional para a Faceli"

07 alunos: “-O tempo que dediquei aos estudos”.

02 alunos: "-????".

07 alunos: "- Amei todas as atividades, foi edificante, novos conhecimentos. Poderia Ter mais momentos síncronos com os professores e entre os acadêmicos”.

Com relação ao que pode melhorar, a grande maioria apontou que as videoaulas no primeiro semestre ficaram longas. Mediante a paralisação das aulas presenciais, os professores gravaram aulas como puderam em seus computadores, com a mesma dinâmica do presencial, afinal, pensaram que seria por pouco tempo. Com o passar dos meses, percebeu-se que a pandemia iria perdurar mais que o esperado e houve necessidade de adequação do material. Mediante este dado, as videoaulas foram fragmentadas em vídeos menores. O ensino presencial permite interações que o momento assíncrono não oferece, por melhor que seja o vídeo, o cérebro humano tem dificuldade de se manter concentrado em um recurso audiovisual por muito tempo como afirmam Bergmann e Sams (2018).

Uma parcela de estudantes tomou para si a pergunta, pois reconheceu que dedicaram pouco tempo aos estudos, que precisam de mais momentos com os professore e com seus pares, o que denota imaturidade para se organizarem sozinhos ou grupos de estudo e de trocas de experiências, o que pode ser reflexo do ensino tradicional e condicionante que tiveram por muito tempo na vida estudantil em que o professor determina o que, o como, quando e onde 


\section{OO DEVIR EDUCAÇÃO}

ISSN: 2526-849X

fazer. A aquisição de autonomia por parte do aluno é um processo demorado e que deve ser incentivado constantemente (MORÁN, 2018).

Com relação ao que foi bom no ensino remoto exercido na Faceli em 2020.1, os estudantes disseram:

25 alunos: “-Atenção dos professores, o atendimento que deram pelo WhatsApp, a flexibilização no cronograma de entregar algumas atividades, trabalhos interdisciplinares e aulas videoaulas dos quais tínhamos a explicação do conteúdo disponível à qualquer momento e lugar".

08 alunos: "-Não sei".

04 alunos: "-Conseguir concluir o período, porém teve nada de bom”.

12 alunos: "-Aprendi a estudar pelas TICs, seja acessando o AVA ou produzindo e editando vídeos, a usar aplicativos, a escrever diversos gêneros textuais, das aulas síncronas e da Avaliação da Aprendizagem”.

Assim como é bom conhecer as fragilidades, melhor ainda é conhecer os êxitos do processo de ensino para o professor saber o que manter ou não no processo educativo. Quanto a isto, mais da metade dos estudantes apontou que foi bom contar com ajuda dos professores pelo WhatsApp para a elucidação de conteúdos, atividades e flexibilização de datas.

Como afirmam Rodrigues e Teles (2019), o WhatsApp é a tecnologia mais presente no momento nas mãos dos estudantes, logo, aderi-lo como ferramenta para os processos de ensino e de aprendizagem é, de certa forma, incluir o estudante no ensino remoto possibilitando-o a participar de forma ativa, visto que muitos deles não possuem outro recurso a não ser este para continuar seus estudos no período pandêmico.

Outra significativa parcela dos acadêmicos gostou de aprender novos gêneros textuais, de lidar com aplicativos de criação e edição de vídeos para apresentar seminários, dos momentos síncronos, das provas e avaliações de aprendizagem realizadas pelo Quis, entre outras atividades diversificadas que tiveram nos FTMs. O fato de serem conscientes da importância destes domínios tecnológicos pode ser um indicativo de que eles perceberam a importância de ensinar e de aprender com o uso intencional das TICs, como afirma Morán (2015; 2018). Estes dados sinalizam que práticas de interação, perguntas relâmpagos para serem respondidas no chat, entre outras metodologias ativas utilizadas, foram proveitosas para a aprendizagem e, portanto, servem de estímulo para continuar nos próximos semestres.

Todavia, neste item é preocupante o fato de 12 estudantes declararem que não foi bom ou que não sabem opinar. À vista disso, se deduz insatisfação com o ensino remoto. Dado que 


\section{OO DEVIR EDUCAÇÃO}

ISSN: 2526-849X

serve de termômetro para o docente perceber que o planejamento deve ser refeito, mas também compreender o outro lado do processo educativo: o fazer do estudante. Alguns deles começaram a trabalhar no período em que estudavam, pois com a pandemia, familiares perderam emprego e tiveram que ajudar nas despesas de casa. Outros moram no interior, em locais onde o sinal de internet na cidade de Linhares-ES é ruim, o que pode ter dificultado acompanhar o processo de ensino feito com uso intensivo de tecnologias.

Ademais, alguns destes acadêmicos que não gostaram do ensino remoto também fazem parte do grupo que está acostumado ao ensino presencial com aulas expositivas dialogadas. Ao mudar de metodologia abruptamente, eles encontraram dificuldade de se adaptar. Todos estes desafios enfrentados pelos discentes não validam como excelente o processo de ensino, mas sinalizam que o êxito de $100 \%$ do processo não é garantido apenas pelo professor como apontam Oliveira; Silva e Silva, (2020).

Estes foram os êxitos e desfechos obtidos nos FTMs em 2020.1 Como afirmam Oliveira, Silva e Silva (2020) a ação emergencial seguida da reflexão pode repercutir em melhores ações futuras e desta forma aperfeiçoar a práxis de ensino, e de fato, esses resultados auxiliaram a melhorar o ensino para 2020.2 com videoaulas mais sucintas e com menos atividade, porém mais significativa visando melhor ensino e aprendizagem.

\section{Considerações Finais}

Mediante os resultados e discussões estabelecidas neste estudo, entendemos que conseguimos atingir o objetivo de relatar experiências e de estabelecer reflexões importantes acerca do processo de ensino e aprendizagem durante a pandemia; as experiências descritas sinalizaram bem a função de cada sujeito na práxis educativa, inclusive do Estado.

$\mathrm{Na}$ enquete realizada com 49 acadêmicos do Curso de Pedagogia, percebeu-se que muitos não conseguiram reservar tempo para estudar em casa, alguns tiveram que trabalhar para ajudar no sustento familiar e muitos não tiveram acesso satisfatório à internet para acompanhar o ensino on-line; logo consideramos que estes foram os principais empecilhos para aquisição de boa aprendizagem durante a pandemia e que COVID-19 configurou muitos 


\section{OO DEVIR EDUCAÇÃO}

ISSN: 2526-849X

problemas no âmbito educacional tanto no Ensino Superior quanto na Educação Básica, pois esses dados não refletem apenas a Faceli, mas também outras instituições de ensino no Brasil.

Todavia, como êxitos, podemos considerar que a exclusão digital de algumas crianças da Educação Infantil de Linhares-ES foi amenizada com vídeos e atividades desenvolvidas pelos futuros Pedagogos sob orientação das mestras responsáveis pelas disciplinas de Estágio e Atividade Prática V. Este feito foi válido para a aprendizagem dos acadêmicos, pois pensaram em novas possibilidades educacionais perante a adversidade social imposta pelo coronavírus e, principalmente, para as crianças e familiares da Educação Básica que foram assistidos e orientados em como dar prosseguimento no processo de ensino de modo que a criança não ficasse estagnada, possibilitando-a progredir na aquisição de habilidades motoras e cognitivas.

Ao que se refere às disciplinas de FTMs, também houve êxitos, pois os acadêmicos progrediram muito, quanto à aquisição de competências digitais. Ocorreu uso estratégico das TICs e isso foi imprescindível para desenvolver Aprendizagens Ativas em que eles criaram autonomia, dinamismo e conhecimento. Desenvolveram raciocínios e habilidades que, dificilmente, adquiririam nas aulas tradicionais em que se recebe de modo passivo e cômodo o conhecimento.

Ficou nítido que ocorreram aprendizagens para docentes e discentes. Ambos desenvolveram habilidades digitais, além de saberes práticos que diferenciam a aula presencial da aula remota. Embora nem todos os estudantes tenham conseguido se adaptar à nova metodologia de ensino, houve significativo número deles que conseguiram aprender, o que contribuiu para ampliar o conhecimento com novos gêneros textuais e também em relação aos recursos audiovisuais.

Contudo, alguns indivíduos se adaptam mais rápido, outros mais devagar, mas a tendência é que todos se adequem ao novo normal e aprendam a desenvolver habilidades para aprender e para ensinar com uso ativo das TICs e de materiais impressos sucintos, objetivos, ilustrativos e atrativos para que o aluno se afinize com a leitura e aprenda de forma autônoma. Cabe às autoridades brasileiras resolverem o problema de inclusão digital dos alunos que não têm condições de fazê-lo, visto que a tecnologia é urgente e necessária em diversas modalidades de ensino antes, durante, e com certeza, também será após a pandemia. 


\section{Referências}

BERGMANN, Jonathan; SAMS, Aaron. Sala de Aula Invertida: uma metodologia Ativa de Aprendizagem. Trad. Afonso Celso da Cunha Serra. [Reimpr.]. Rio de Janeiro: LTC, 2018.

BRASIL. Ministério da educação. Base Nacional Comum Curricular. Brasília: MEC, 2017.

BRASIL. Ministério da Educação. Conselho Nacional de Educação. Câmara de Educação Básica. Resolução $\mathbf{N}^{\mathbf{0}}$ 5, de 17 de dezembro de 2009. Fixa as Diretrizes Curriculares Nacionais para a Educação Infantil. Brasília: MEC/CNE/CEB, 2009.

BRASIL. Ministério da Educação. Conselho Nacional de Educação. Resoluçãa CNE/CP No 2, de 10 de dezembro de 2020. Brasília: MEC/CNE, 2020.

BRASIL. Ministério da Educação. Gabinete do Ministro. Portaria $\mathbf{N}^{\circ}$ 544, de 16 de junho de 2020. Brasília: MEC, 2020.

BRASIL. Ministério da Educação. Portaria no 343, de 17 de março de 2020. Dispõe sobre a substituição das aulas presenciais por aulas em meios digitais enquanto durar a situação de pandemia do Novo Coronavírus - COVID-19. DOU - Imprensa Nacional [Internet]. Disponível em: <http://www.planalto.gov.br/CCIVIL_03/Portaria/PRT/Portaria\%20n\% C2\%BA\%20343-20-mec.htm>. Acesso em: 25 mar. 2020.

BRASIL, UNA-SUS: Organização Mundial de Saúde declara pandemia do novo Coronavírus. (2020). Disponível em: https://www.unasus.gov.br/noticia/organizacaomundialde-saude-declara-pandemia-de-coronavirus. Acesso em: 02 set. 2021.

ESPÍRITO SANTO. Governo do Estado do Espírito Santo. Secretaria de Educação. Currículo do Espírito Santo. SEDU/Undime: Vitória, 2018.

FIGUEIREDO, Marília Z. A; CHIARI, Brasilia M; GOULART, Bárbara N. G. de. Discurso do Sujeito Coletivo: uma breve introdução à ferramenta de pesquisa qualiquantitativa. Distúrbios da Comunicação, v. 25, nº 1, 2013.

FREITAS, Joana Lúcia Alexandre de. A Pandemia da COVID-19 e o Ensino Remoto em Linhares-ES. Revista Kiri-kerê: Pesquisa em Ensino, n.9, dez. 2020.

FREITAS, Joana Lúcia Alexandre de; MACEDO, Yuri Miguel. BLACK POWER: UM PROJETO EMANCIPATÓRIO E ANTIRRACISTA NA FACELI. @ rquivo Brasileiro de Educação, Belo Horizonte, v. 8, n. 17, 2020.

FUNDAÇÃO FACELI. Plano de ações elaborado pelo grupo de trabalho multissetorial Fundação FACELI - 2020 Covid-19. Linhares, 2020. Disponível em: <https://faceli.edu.br/wp-content/uploads/2020/07/PLANO-DO-GTMFUNDA\%C3\%87\%C3\%830-FACELI-COVID-19.pdf>. Acesso em: 25 mar. 2020.

GIL, Antônio Carlos. Métodos e técnicas de pesquisa social. $7^{\text {a }}$ ed. São Paulo: Atlas, 2019.

Revista Devir Educação, Lavras-MG. Edição Especial, p.161-182, Set./2021. 


\section{OO DEVIR EDUCAÇÃO}

ISSN: 2526-849X

IBGE - INSTITUTO BRASILEIRO DE GEOGRAFIA E ESTATÍSTICA. IBGE Panorama- População: domicílios com acesso à internet. Brasília: Ipea, 2019. Disponível em: 〈https://cidades.ibge.gov.br/brasil/panorama〉. Acesso em: 2 set. 2020.

LINHARES. Secretaria Municipal de Educação. Orientações Curriculares da rede municipal de ensino de Linhares, 2019.

LEAL, José. Um momento para reinvenção individual e coletiva. In.: Novo normal, Panorama 66: JORNAL DA UNIVERSIDADE FEDERAL DE CIÊNCIAS DA SAÚDE DE PORTO ALEGRE, ANO XII, nº 66 , dezembro 2020/janeiro/fevereiro 2021. Disponível em: < https://www.ufcspa.edu.br/documentos/ascom/panorama66/panorama66.pd $>$. Acesso em: 02 set. 2021.

MORÁN, José. Metodologias ativas para uma aprendizagem mais profunda. In. BACICH, Lilian; MORÁN, José (org.). Metodologias Ativas para uma educação inovadora: abordagem teórico-prática. Porto Alegre: Penso, 2018.

MORÁN, José. Mudando a educação com metodologias ativas. In: SOUZA, C.A.; MORALES, O. E. T. (orgs.). Convergências Midiáticas, Educação e Cidadania: aproximações jovens. Coleção Mídias Contemporâneas. Vol. II. PG: Foca FotoPROEX/UEPG, 2015, pág. 15-33. Disponível em: <http://www2.eca.usp.br/moran/wpcontent/uploads/2013/12/mudando_moran.pdf $>$. Acesso em: 25 mar. 2021.

OLIVEIRA, Sidmar da Silva; SILVA, Obdália Santana Ferraz; SILVA, Marcos José de Oliveira. Educar na incerteza e na urgência: implicações do ensino remoto ao fazer docente e a reinvenção da sala de aula. Interfaces Científicas, v.10, n.1, p. 25-40, 2020.

PIMENTA, Selma Garrido; LIMA, Maria Socorro Lucena. Estágio e docência. 8. ed. São Paulo: Cortez, 2017.

RODRIGUES, Tereza Cristina; TELES, Lucio França. O uso de mensagens eletrônicas instantâneas como recurso didático. Rev. Bras. Estud. Pedagog. v.100, n²54, Jan/Abr. 2019.

RONDINI, Carina Alexandra; PEDRO, Ketilin Mayra; DUARTE, Cláudia dos Santos. Pandemia da covid-19 e o ensino remoto emergencial: mudanças na prática pedagógica. Interfaces Científicas, v.10, n.1, p. 41-57, 2020.

SANTOS, Edméa. EAD, palavra proibida. Educação online, pouca gente sabe o que é. Ensino remoto, o que temos. Notícias, Revista Docência e Cibercultura, agosto de 2020, online. ISSN: 2594-9004. Disponível em: <https://www.e-publicacoes.uerj.br/index.php/redoc/announcement/view/1119>. Acesso em: 01 set. 2021.

SANTOS, Glauco de Souza. Espaços de aprendizagens. In.: BACICH, L.; TANZI NETO, A.; TREVISANI, F. de M. (Orgs.) Ensino Híbrido: Personalização e Tecnologia na Educação. Porto Alegre: Penso, 2015. Atualização maio/2019.

Revista Devir Educação, Lavras-MG. Edição Especial, p.161-182, Set./2021. 
SCHNEIDER, Fernanda. Otimização do espaço escolar por meio do Modelo de Ensino Híbrido. In.: BACICH, L.; TANZI NETO, A.; TREVISANI, F. de M. (Orgs.) Ensino Híbrido: Personalização e Tecnologia na Educação. Porto Alegre: Penso, 2015. Atualização maio/2019.

SILVA, Carla Marins et al. Pandemia da COVID-19, ensino emergencial à distância e Nursing Now: desafios à formação em enfermagem. Rev Gaúcha Enferm, nº 42, 2021.

Recebido em: 01/07/21

Aprovado em: 08/09/21 